\title{
PROCESSO DE INSTITUCIONALIZAÇÃO DA FORMAÇÃO DA MULHER NO SÉCULO XIX
}

Teresinha Venturin*

SÍNTESE - O presente estudo faz uma análise da institucionalização da formação da mulher das camadas populares de Porto Alegre, no século XIX. Em decorrência da transformação social, econômica e política, tornou-se necessário um empenho sistematizado para inserir a menina órfã na sociedade, transformando a jovem na mãe e educadora por excelência.
ABSTRACT - The present study analyzes the institutionalization of the education of women from the popular strata of Porto Alegre, in the $19^{\text {th }}$ century. As a consequence of the social, economical and political transformation, it became necessary to bring forth a systematized effort in order to insert the orphan girl in society, transforming the young woman in the mother and educator beyond comparison.

\section{Introdução}

Este artigo se constitui em um espaço de formação e aprendizado na articulação entre teoria e dados, como resultado das pesquisas desenvolvidas junto às instituições fundadas pelo Pe. Joaquim Cacique de Barros. Pretende-se aqui expor como a institucionalização de meninas se efetivou através de um conjunto de práticas educativas e assistenciais, implementado pelo Padre Cacique em Porto Alegre, no período de 1860 a 1940.

O referencial de análise baseia-se no pressuposto de que, com o decorrer do tempo, as rupturas na trajetória dessas instituições estão associadas à dinâmica estrutural do campo religioso que se articula interativa e/ou conflitivamente com o campo político, econômico e social. Os dados coletados através de vários procedimentos e fontes referem-se aos asilos Santa Tereza, de Mendicidade e São Joaquim, fundados em diferentes épocas do século XIX.'

* Bacharel em Ciências Socjais e bolsista de Aperfeiçoamento - CNPq, junto ao Projeto Integrado, sob a orientação da Prof ${ }^{a}$ Julieta Beatriz Ramos Desaulniers.

1 O Padre Cacique fundou em 1865 o asilo Santa Tereza para a formação da menina órfã. $O$ asilo de Mendicidade foi fundado em 1881 para recolher velhos, mendigos e pessoas decrépitas e, na virada do século, foi fundado o asilo São Joaquim, com o objetivo de criar e educar crianças desamparadas.

\begin{tabular}{|l|l|l|l|l|r|}
\hline VERITAS & Porto Alegre & v. 42 & $\mathrm{n}^{\circ} 2$ & Junho 1997 & p. 217-222 \\
\hline
\end{tabular}


O início da educação feminina institucionalizada data de 1778, com a fundação da Casa das Recolhidas na Aldeia dos Anjos, para a formação da menina india. Esta casa era administrada pelo Padre Vigário da Igreja local e tínha como professora Dona Gregoria Rita Coelho, conhecedora da língua guarani. Após a gestão do Governador Marcelino de Figueiredo, a casa não recebeu mais incentivos, tendo surgido, então, outras iniciativas de ensino publico, principalmente durante o Primeiro Reinado. Ao contrário da Casa das Recolhidas, nessas novas casas não havia professoras. Em 15 de outubro de 1827, uma Carta-lei previa a educação de meninas, ${ }^{2}$ porém a falta de professores para atuar no magistério e os baixos salários agravavam o problema da instrução. O governo passou então a nomear professoras para suprir as vagas existentes. Em 1835, todavia, o Movimento Farroupilha desorganizou as iniciativas de educação pública.

Na segunda metade do século XIX, o Rio Grande do Sul entrava em nova fase de mudança social, econômica e política, com a chegada dos imigrantes, vindos principalmente dos países europeus. O campo religioso começa então a se definir, ocupando espaços próprios.

Nessa época, Porto Alegre apresentava um número significativo de crianças órfãs e pobres devido, sem dúvida, à Revolução Farroupilha. Dom Pedro II, que havia estado em Porto Alegre em 1845, determinara a fundação de um asilo para as meninas órfãs, denominado Santa Tereza. Várias comissões foram organizadas para a construção desse asilo, porém nenhuma delas levou a termo a tarefa. Somente com a vinda para Porto Alegre do Padre Joaquim Cacique de Barros, em 186l, concretizaram-se os objetivos propostos pelo Imperador.

O governo já havia assinado várias leis e provisões que regulamentavam a educação sem, contudo, obter resultados satisfatórios. Preocupado em solucionar os problemas da instrução, passou a confiar a educação das meninas desvalidas e pobres aos sacerdotes e professores. Para isso, a 5 de abril de 1869, o Presidente da Província criava a Escola Normal, que seria anexada ao Liceu, ${ }^{3} \mathrm{com}$ a finalidade de preparar professores para o ensino primário. O funcionamento dessa Escola iniciou em $1^{\text {10 }}$ de maio de 1869 , sob a direção do Padre Joaquim Cacique de Barros, com doze alunos matriculados, oito rapazes e quatro moças. ${ }^{4}$

Ao reconstituir o processo de formação instaurado pelo Padre Cacique em suas instituições, procurou-se investigar os atos e estratégias que dependem mais de um conjunto de "disposições", desencadeados por esse agente do campo religioso que, fortalecendo estruturas, passou a ocupar novos espaços e, ao mesmo tempo, ampliou sua capacidade de estruturação.

2 MUNZ, Paulo Ricardo e Outros. Lugar de mulher: pequena história da educação feminina em Porto Alegre, 1820/1840. Porto Alegre, Ed. Unidade Editorial, 1993.

3 O Liceu de D. Afonso é fundado em 1846. É o primeiro prédio construido, pelos cofres do governo, para abrigar uma escola pública da Provincia, para o ensino secundário. As aulas tem o seu inicio em 1851.

1 MUNIZ, Paulo Ricardo. Op. cit. , p. 20.

s BOURDIEU, Pierre. A economia das trocas simbólicas. São Paulo, Ed. Perspectiva, 1992, p. XI. 


\section{I - Construção da imagem das instituições}

Desde sua chegada a Porto Alegre, o Padre Cacique se destacou por sua austeridade, sobriedade e diligência. Devido a seu caráter, sua "cor morena de tez, seu pai comparava-o a um chefe de tribo", ${ }^{\circ}$ chamando-o de Cacique.? Essa postura de Cacique, seu traço característico, possibilitou a ampliação do campo religioso e sua estruturação frente aos diferentes campos do espaço social, durante muitos anos, especialmente na formação das jovens das camadas populares de Porto Alegre.

Padre Cacique recolhia, sustentava e educava as meninas desvalidas, com o objetivo de inseri-las novamente na sociedade. Para esse fim, valeu-se de seu capital religioso e cultural, ${ }^{8}$ ou de seu habitus, ${ }^{9}$ em parte adquirido em sua cidade natal, Salvador/Bahia e no antigo Colégio Pedro II no Rio de Janeiro.

O conjunto de saberes acumulados gerava um conhecimento que o tornou famoso como educador exemplar, cheio de virtudes, no seio das principais famílias porto-alegrenses. Em 1880, o asilo Santa Leopoldina, que recolhia os expostos ${ }^{10}$ da Santa Casa, foi incorporado ao asilo Santa Tereza, com 48 órfãs, passando a ser considerado um centro de formação da menina órfã. Os recursos financeiros do Estado destinados ao asilo Santa Leopoldina foram repassados, então, ao asilo Santa Tereza.

Em 1881, devido a uma série de conflitos com o corpo docente, o Pe. Cacique demite-se da Escola Normal e passa a se dedicar totalmente ao asilo Santa Tereza e à fundação do Asilo de Mendicidade, destinado a recolher os velhos e mendigos da cidade. Para a construção da casa do asilo, o Pe. Cacique saía com sua carroça, batendo de porta em porta, pedindo donativos. Ele dizia rindo: "obra grande se faz com pouco dinheiro". As primeiras contribuições foram de suas próprias educandas $^{11}$ que recebiam instrução e, em troca, ajudavam a prover as necessidades das colegas. Isso, porém, não era tudo: ele era conhecido internacionalmente e recebia muitas doações. Se folhearmos os relatórios do Santa Tereza enviados ao Presidente da Província ou à Administração, veremos os pedidos e justificativas da necessidade de verbas para suas instituições. O Padre Cacique orgulhava-se de ser um dos maiores pedintes da cidade.

Em maio de 1892, ele funda a Sociedade Humanitária Padre Cacique, tendo na diretoria pessoas ilustres de Porto Alegre. A finalidade desta instituição está

6 RIBEIRO, José. O Padre Joaquim Cacique de Barros na Hierarchia da caridade. in Anuário do Estado do RGS/1909 de Graciliano Azambuja. Porto Alegre, Ed. Gundlach \& Cia Livreiros, 1909.

7 Cacique foi o apelido dado por seu pai e incorporado a seu nome.

\& Além da Teologia e Filosofia, cursou Ciências Fisicas, Letras e Matemática. Lecionou no Gynasio Bahiano de ensino superior, fundado pelo educador Dr. Abílio César Borges com sua experiência de professor no antigo colégio Pedro II no Rio de Janeiro.

- Habitus é um conhecimento adquirido, um capital, indicando uma disposição incorporada - uma preocupação especial por parte de um agente em ação (BORDIEU, P. O poder simbólico. Rio de Janeiro, Ed. Bertrand Brasil, 1989, p. 61.).

10 Expostos, nome dado às crianças que eram deixadas por suas mães na Santa Casa de Misericórdia de Porto Alegre, para serem "adotadas" por outra família.

$"$ VIANNA, José Gonçalves. Biografia do Padre Joaquim Cacique de Barros in Anuário do Estado do Rio Grande do Sul/1984, de Graciliano de Azambuja. Porto Alegre, Ed. Gundlach \& Cia, Livreiros, 1893, p. 103. 
sintetizada nos estatutos da mesma. Com seu nobre ideal de caridade, e já na virada do século, projetava a construção do asilo São Joaquim para meninos desamparados, quando a morte o surpreendeu, em 12 de maio de 1907 aos 76 anos.

\title{
II - O processo de institucionalização da formação da mulher
}

No século XIX, a formação feminina passa a ser considerada de suma importância, e o casamento, um dos meios de ascensão social. A imagem da mulher era idealizada e reproduzida como o símbolo da pureza, da beleza e da sedução. Mas, por outro lado, devido à necessidade de suprir a falta de mão-de-obra nas escolas primárias, o magistério se apresenta como uma oportunidade de trabalho, e a mulher torna-se assim a educadora por excelência.

Com essa preocupação, Padre Cacique oferecia às suas educandas um aprendizado fundado na aquisição de experiências concretas, vividas no quotidiano, que exigia a construção de uma nova identidade, garantindo desse modo maior rendimento no trabalho, tudo conforme os princípios da moral e da ética cristãs. José Gonçalves Vianna, biógrafo do Padre Cacique, ao escrever sobre a formação proporcionada no Colégio Santa Tereza, diz:

\begin{abstract}
"[...] ensina-se tudo quanto constitue o preparo sério e sólido de uma moça tanto em conhecimentos indispensáveis, como em trabalhos próprios de seu sexo e seu destino. Estudo e labor distribuídos com muito critério e sustentados com delicada disciplina fazem a vida e a reputação desse colégio, que está efetivamente sob os auspícios do Pe. Cacique $[\ldots]^{p 12}$
\end{abstract}

No colégio Santa Tereza, as moças recebiam ensinamentos úteis: lições de Astronomia prática, "leituras de revistas científicas e obras literárias, manuseavam tratados de Física, Química, Mecânica e tudo quanto pudesse não só nutrir a inteligência", mas multiplicar seus conhecimentos. ${ }^{13}$ Esse aprendizado ia produzindo uma geração de mulheres voltadas à vida ordeira, disciplinada e, ao mesmo tempo, requintada, que assegurava o desenvolvimento de habilidades da futura mãe ou da profissional de qualquer atividade.

O Padre Cacique, que sempre se distinguiu dos demais agentes sociais por sua capacidade intelectual e moral, dirigiu a Escola Normal até 1881. Ao demitirse da Escola, porém, levou com ele as alunas e passou a proporcionar-lhes outras espécies de aprendizado, mais prático e artesanal, chegando a montar uma pequena fábrica de roupas por elas mesmas confeccionadas. Esse trabalho se realizava com as alunas em regime de internato, o que conferia ao processo uma certa dinâmica, fortalecendo desse modo o poder institucional, uma vez que a instituição recebia as crianças em uma espécie de "adoção" - os responsáveis pela criança assinavam junto ao órgão competente do Estado um documento de "desistência do pátrio poder"."

VIANNA, José Gonçalves, op. cit., p. 104.

VIANNA, José Gonçalves, op. cit., p. 109.

"desistência do direito do pátrio poder" significava entrega da criança à responsabilidade total da instituição, podendo esta trocar o nọme da criança, batizá-la na Igreja Católica caso fosse de outra religião e assim por diante. 
De outra parte, a instituição, visando capacitar suas educandas para enfrentar os desafios da época e buscando inseri-las na ordem social, estabelecia rotinas bem organizadas e atividades adequadas, de modo a formar excelentes professoras e ótimas mães de família. O processo de formação instaurado por esse agente do campo religioso, o Pe. Cacique, em suas instituições, foi reconhecido pela sociedade porto-alegrense e durou até 1945, quando então houve a intervenção do Estado nas instituições do Padre Cacique.

\section{III - As instituições após a intervenção}

Por volta de 1940, o Rio Grande do Sul passa por um período de crises: dificuldades na pecuária, decadência das charqueadas, intensificação do êxodo rural e problemas na lavoura colonial. Para enfrentar a situação adversa, em 1942 começa a "grande estruturação administrativa e burocrática". A educação separa-se da saúde e tem como principal objetivo a implantação da Escola Nova, com conceitos e princípios vindos da Europa e Estados Unidos, e defende um ensino integrador e total. ${ }^{15}$ Nesse projeto de reestruturação burocrática, criou-se no Estado um grande projeto de Assistência Infantil, assim noticiado pelo jornal Correio do Povo: "O governo do Estado destinará cerca de quatro milhões de cruzeiros à Assistência Infantil". É nesse contexto político interventor por que passou o Estado que, em agosto de 1945, é decretada a intervenção na Sociedade Humanitária Padre Cacique. Nessa época, o Asilo Santa Tereza necessitava de consertos, por isso as crianças foram transferidas para o Asilo São Joaquim. Em 21 de setembro de 1945, o jornal publica nota dizendo que:

“[...] o Asilo Santa Tereza está desocupado e que a Sociedade Humanitária Padre Cacique não o aproveitava ultimamente. E após limpeza, pinturas e consertos em algumas esquadrias e telhado, prestar-se-á para 150 menores delinqüentes agora recolhidos à casa de correção". ${ }^{16}$

Depreende-se do que foi dito acima que, nessa época, as instituições do $\mathrm{Pa}$ dre Cacique haviam como que se deteriorado, mudando seus objetivos e clientela. Um fator que contribuiu decisivamente para essas mudanças foi, sem dúvida, a proliferação das Congregações Religiosas que se estabeleceram no Rio Grande do Sul desde os fins do século XIX e início deste, com escolas particulares dedicadas ao ensino feminino. Além disso, o começo do século é marcado por iniciativas de emancipação profissional das mulheres, e 0 asilo Santa Tereza e outras instituições que tinham a missão de formar professoras e mães de família perderam um pouco de sua importância e passaram a ter outra finalidade: receber menores delinqüentes do Estado.

Atualmente, a Sociedade Humanitária continua mantendo suas funções, dentro do mesmo espírito de seu fundador, coordenando os trabalhos no Asilo de

${ }^{15}$ NUNES, José Luiz M. A educação no Rio Grande do Sul, in Aspectos da Geografia. Porto Alegre, Martins Livreiro Editor, 2a. ed. 1992, p. 88.

${ }^{16}$ A propósito da intervenção nos asilos pelo Governo do Estado - em 1945, p. 1. Arquivo da Sociedade Humanitária Padre Cacique. 
Mendicidade, que atende pessoas abandonadas, velhos e mendigos de Porto Alegre e até de outras localidades.

\section{5 - Considerações finais}

De todo o exposto, podemos concluir que a formação feminina implementada pelo Padre Cacique foi-se adaptando às mudanças no decorrer de seu processo de institucionalização.

Por outro lado, o desenvolvimento das instituições dedicadas à educação das mulheres das camadas populares da cidade está relacionado a uma organização e planejamento que permitiram a articulação da sociedade porto-alegrense com os diferentes campos sociais. Pelos dados colhidos, percebe-se que as instituições criadas pelo Padre Cacique durante o período de 1860 a 1945, conseguiram garantir e consolidar o campo religioso ao lado do econômico e político dentro do espaço social e manter-se solidárias com comerciantes, políticos e empresários para atingir seu principal objetivo: "dar às meninas órfãs formação da mãe educadora do lar e da professora, a educadora por excelência". Sem dúvida, esse tipo de formação visava operacionalizar a construção de um conjunto de saberes, instaurando um novo habitus, condizente com o modelo de mulher que então se instituía. 